\title{
O.Ashm. 104: Requisitioned pillows and their prices ${ }^{1}$
}

The first five lines of O.Ashm. 104 were initially published as O.Crum Ad. 31, which was described as follows: 'List of names with sums of money and other figures opposite them. There are more on the ostr. but none are remarkable.' Tait was unaware of this publication, as the problematic readings in lines 1-2 and 4 imply. A revised edition is given below. The 'Coptic' character of the hand, as well as the spelling, suggests that this should be treated as a Coptic text, hence the resolution of the patronymics in the nominative.

Crum noted: 'I cannot complete the abbreviation $\pi \lambda \mathrm{o}$ or $\pi \mathrm{o} \lambda$ ', which is also found in another text he published, O.Crum 447: 'Names of men and women, with their fathers, have opposite them the obscure abbreviation $p l$ and the figure $\alpha$.' Women are mentioned in O.Ashm. 104 too $(1 ; ? 11)$. The abbreviated word ( $\pi$ with $\lambda$ suprascript) recurs in O.Petr.Mus. 578 , also written in a 'Coptic' hand, where the abbreviation is invariably followed by the number ' 1 ', and in O.Petr.Mus. 583, where the figures range from 1 to 8 , and alternate with entries referring to solidi (see A. Delattre, J.-L. Fournet, APF 59 (2013) 170); see also in BKU III 466r, which lists names, money and $\square \square \square$. F. Morelli (per litt.) has made the attractive and

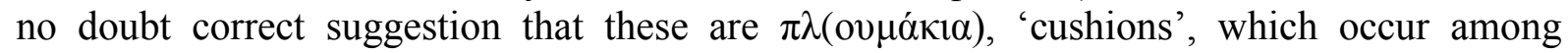
requisitions by the state authorities in the late seventh and early eighth centuries. The amounts of money that precede them would be their prices, but no consistent pattern emerges. ${ }^{2}$

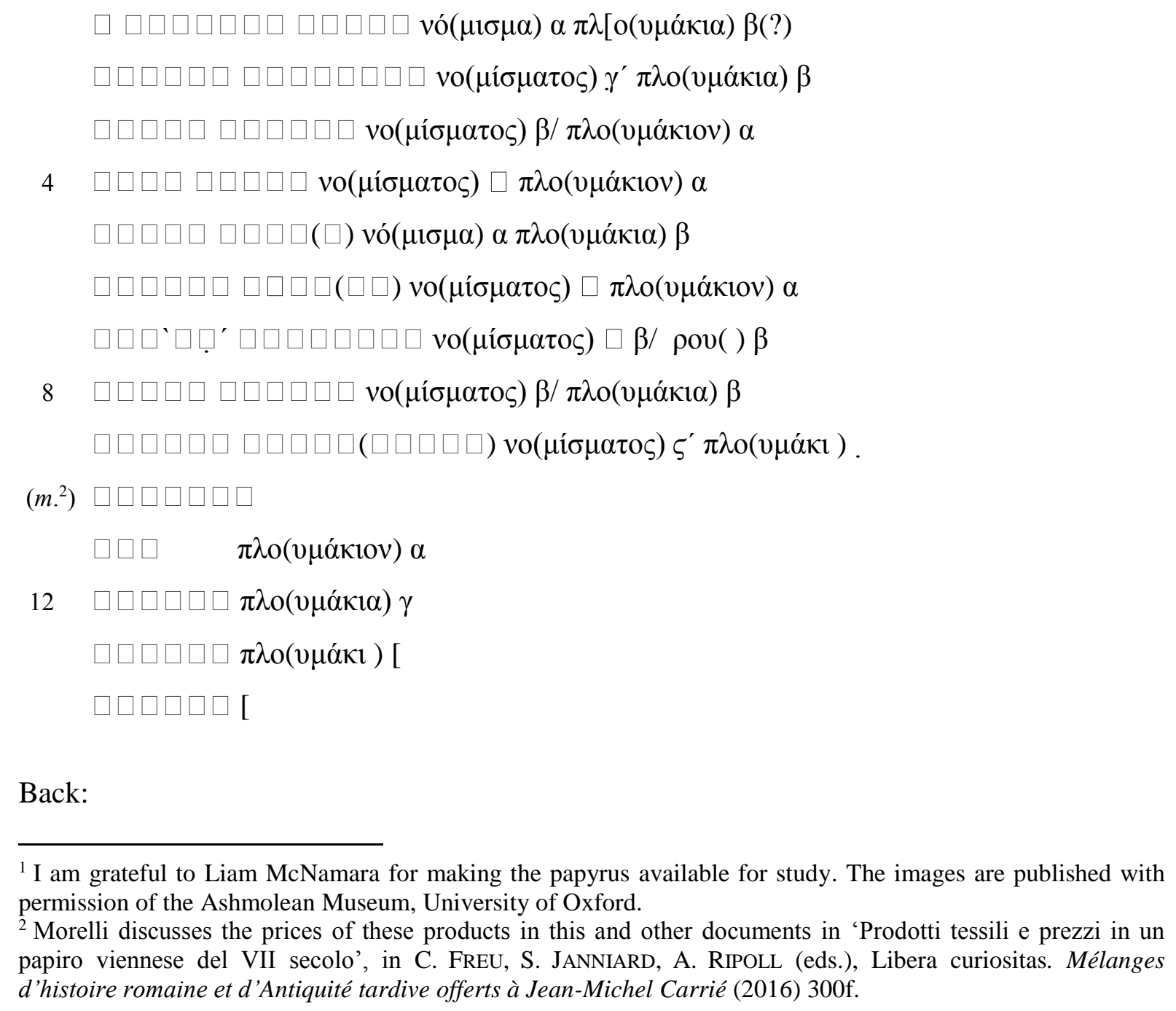

Back:

\footnotetext{
${ }^{1}$ I am grateful to Liam McNamara for making the papyrus available for study. The images are published with permission of the Ashmolean Museum, University of Oxford.

${ }^{2}$ Morelli discusses the prices of these products in this and other documents in 'Prodotti tessili e prezzi in un papiro viennese del VII secolo', in C. FREU, S. JANNIARD, A. RIPOLL (eds.), Libera curiositas. Mélanges d'histoire romaine et d'Antiquité tardive offerts à Jean-Michel Carrié (2016) 300f.
} 
$\left(m \cdot{ }^{1}\right)$ $v o(\mu i ́ \sigma \mu \alpha \tau \alpha) \varsigma \pi \lambda \mathrm{o}(v \mu \alpha ́ \kappa i \alpha) i \beta$

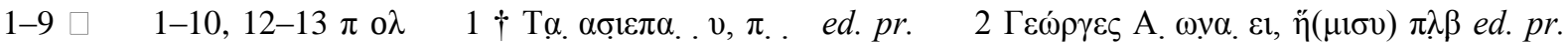

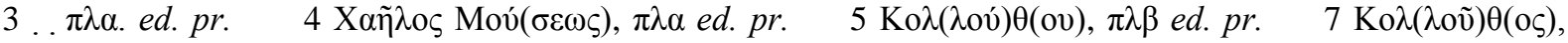

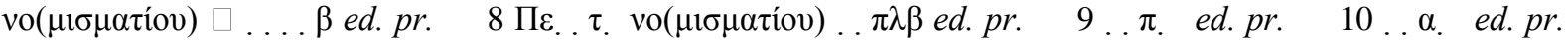
$11 \ldots$ ed. $p r . \quad 12 \ldots . . \pi$. $\gamma$ ed. $p r . \quad 13 \Theta \varepsilon \omega . \rho \varepsilon[$ ed. $p r . \quad 15$ not reported in $e d . p r$.

Tanaste daughter of Paleu: sol. 1, cushions 2(?); George son of Sanagape: sol. 1/3, cushions 2; Kosma son of Symeon, sol. $2 / 3$, cushion 1; Chael son of Psmou: sol. 1/2, cushion 1; Kosma son of Kolthe: sol. 1, cushions 2; Symeon son of Viktor: sol. 1/2, cushion 1; Kolthe son of Theodoros: sol. $1 / 2 \frac{2}{3}$, red(?) 2; Kosma son of Pes(y)nte: sol. $2 / 3$, cushions 2; Markos son of Anastasios: sol. 1/6, cushion $n$; (2nd hand) Severos; Lia: cushion 1; Kamul: cushions 3; Theod(o)re: cushion $n$; David ... (back) (1st hand) Matthaios son of Pses: sol. 6, cushions 12.

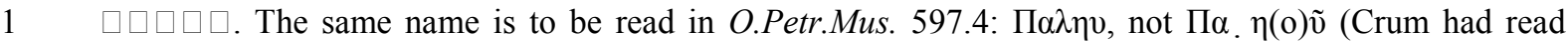
$\Pi \alpha . \eta^{0}$, but put ' $\mathrm{Pa}(\mathrm{i})$ êu' in the translation; see O.CrumVC p. 48, no. 121).

W. C. Till, Datierung und Prosopographie der koptischen Rechtsurkunden aus Theben (SBWien 240.1: 1962) 91, cites another instance from O.Brit.Mus.Copt. I pl. XIVa.3.

$\gamma^{\prime}=$. Crum read $\square$; Tait saw the same letter too, but this is hardly $\eta^{\prime}$. The unusual shape is mostly due to the fact that the rising oblique that functions as a fraction marker starts from low in the lime, somewhat like that for $\varsigma^{\prime}$ in line 9 .

$\beta$. The top of the letter is lost, but the lower part suggests beta rather than alpha.

$3 \operatorname{vo}(\mu.) \beta /$. The same figure occurs in lines 7 and 8 . Crum read $\square$, which is impossible.

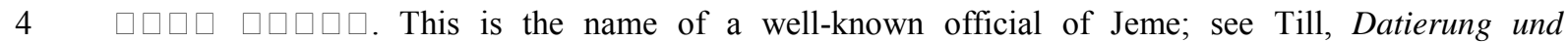
Prosopographie 68.

$5 \quad \square \square \square \square(\square)$ rather than $\square \square \square(\square \square \square) \square(\square \square)$; see next note.

$7 \quad \square \square \square \square \square$ '. The scribe's intention was apparently to abbreviate the name as in 1.5 , but added another stroke after theta, which makes the sequence compatible with $\square$.

The sequence $\square \beta /, 1 / 2 / 3$, is anomalous, but it looks as if the second fraction was a later addition. It is less likely that the fraction for $1 / 3$ should be read instead of $2 / 3$.

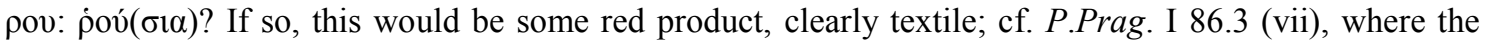
word is used as a substantive.

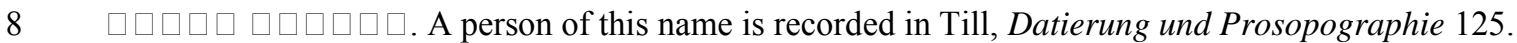

$9 \quad \begin{aligned} & 9 \\ & 9\end{aligned}$

$\pi \lambda \mathrm{o}(\mathrm{v \mu \alpha ́} \kappa \iota)$. . The surface is damaged and no reading can be confirmed.

$10-11$ It is unclear whether $\pi \lambda \mathrm{o}() \alpha$ is to be taken with the name in 1.10 or that in 11 . The two names should probably not be taken together, not so much because $\square \square \square$ is feminine, but because the lines that follow 
only refer to single names. As A. Delattre points out to me, lines 10-14 are written by a second hand, which also accounts for the different structure of the text: no names of fathers and sums in solidi are mentioned. 